\title{
A STUDY ON BLENDING CHARACTERISTICS OF AXIAL FLOW IMPELLERS
}

\author{
Ivan Fořt" and Tomáš Jirout \\ Czech Technical University in Prague, Faculty of Mechanical Engineering, Department of Process \\ Engineering, Technická 4, 16607 Prague 6, Czech Republic
}

\begin{abstract}
This paper presents an analysis of the blending characteristics of axial flow high-speed impellers under a turbulent regime of flow of an agitated low viscosity liquid. The conductivity method is used to determine the time course of blending (homogenisation) of miscible liquids in a pilot plant fully baffled mixing vessel, and a torquemeter is used for measuring the impeller power input in the same system. Four-blade and six-blade pitched blade impellers and three high efficiency axial flow impellers are tested for the given degree of homogeneity ( $98 \%)$.

The experimental results and also the results of the authors' previous study, in accordance with the theoretical approach described in the literature, show that there is a universal relationship between the impeller power number and the dimensionless blending time, taking into consideration the impeller-to-vessel diameter ratio, independent of the geometry of the axial flow impeller but dependent on the degree of homogeneity. This relationship is found to be valid on a pilot plant scale under a turbulent flow regime of an agitated liquid.
\end{abstract}

Keywords: axial flow impeller, pitched-blade impeller, turbulent flow, impeller power input, blending time

\section{INTRODUCTION}

Blending (homogenisation) is a common operation in chemical and process industries. Until now $80 \%$ of application processes have consisted of blending, and $50 \%$ of processes have dealt with a solidliquid suspension (Seichter and Pešl, 2005). For these operations, axial high-speed impellers are widely applied, because their flow characteristics (pumping capacity, total volumetric flow rate) significantly affect the rate of homogenisation of the liquid phase in an agitated charge (Fořt, 1986; Grenville and Nienow, 2003).

Several parameters describe blending efficiency, whereby blending time is the most important. Blending time is defined as the time necessary to achieve a given homogeneity from the non-equilibrium level after a small volume of tracer has been injected into the mixing vessel (Procházka and Landau, 1961).

In the turbulent flow regime of an agitated liquid, the dimensionless blending time $n \Theta$ for a batch stirred with a single impeller is independent of the impeller's Reynolds and Froude numbers (Khang and Levenspiel, 1953; Kramers et al., 1953; Procházka and Landau, 1951). Grenville and Nienow (2003) proposed a correlation for blending time to reach 95\% homogeneity for various types of single high-speed impellers under a turbulent regime of flow, as follows:

*Corresponding author, e-mail: Ivan.Fort@fs.cvut.cz 


$$
P o^{1 / 3} n \Theta_{0.95}\left(\frac{D}{T}\right)^{2}=5.2,(H / T=1)
$$

with the standard deviation of the constant on the right hand side of Eq. (1) $\pm 10 \%$.

The power number describing the dimensionless impeller power input $P$ is defined as

$$
P o=\frac{P}{\rho n^{3} D^{5}}
$$

Equation (1) is based on the fundamental turbulence concept (Nienow, 1997), in which the macroscale of the turbulence is related to the diameter of the mixing vessel, and the critical local energy dissipation rate in an agitated batch is that at the vessel wall.

The degree of homogeneity of the charge is defined by Grenville and Nienow (2003) as

$$
I(\Theta)=\frac{\left\langle(\Theta)-c_{0}\right.}{c_{\infty}-c_{0}}
$$

or by Procházka and Landau (1961) and Fořt (1989) as

$$
I^{\prime}(\Theta)=\frac{\left\langle(\Theta)-c_{\infty}\right.}{c_{0}-c_{\infty}}
$$

Quantities $c_{0}$ and $c_{\infty}$ express the initial and final concentration of the dissolved matter in an agitated batch, respectively, and the quantity $\langle c(\Theta)>$, depending on time $\Theta$, is defined as an average value of the concentration in the whole volume of the agitated batch, except for the volume of the tracer. When a few (e.g. conductivity) probes are sited in representative locations of a pilot plant mixed batch, their signal does not depend for higher values of quantity $I$ on time $\Theta$ (Grenville and Nienow, 2003), and the average concentration value $\langle c(\Theta)>$ can be replaced by the measured local concentration value. However, it is necessary to select properly the position of the single probe in order to avoid the influence of poorly mixed subregions of the batch (Procházka and Landau, 1961). The degrees of homogeneity defined by Eqs. (3) and (4) are mutually related as

$$
I^{\prime}(\Theta)=1-I(\Theta)
$$

It follows from the solution of the differential mass transfer equation describing blending (homogenisation) in an agitated batch (Procházka and Landau, 1961; Fořt, 1989) that the dimensionless blending time depends on the degree of homogeneity in a logarithmic form

$$
n \Theta_{I^{\prime}}=C \ln \left(L / I^{\prime}\right)
$$

Parameter $L$ in Eq. (6) characterises the initial conditions of homogenisation, and its value is expected to be

$$
L \approx 1
$$

From Eq. (6) and (7) it follows that, for their given geometry and for the size of the mixing vessel, it is possible to recalculate the blending time from the known value of the degree of homogeneity to another selected value, according to the relation

$$
\frac{n \Theta_{I_{1}}}{n \Theta_{I_{2}}^{\prime}}=\frac{\ln I_{1}^{\prime}}{\ln I_{2}^{\prime}}
$$

The form of Eq. (7) corresponds to the calculation of the ratio $n \Theta_{I_{1}} / n \Theta_{I_{2}}$ derived for the degree of homogeneity defined by Eq. (3) (Grenville and Nienow, 2003). 
With the help of the above mentioned relations, this study presents an analysis of the blending characteristics of axial high-speed impellers based on experimental determination of the time course of the blending process created by the investigated impellers under a turbulent flow regime of an agitated batch, and on the basis of determining their power characteristics in the same pilot plant system.

\section{EXPERIMENTAL}

The experiments were carried out in a pilot plant flat bottomed cylindrical vessel (diameter $T=300 \mathrm{~mm}$ ) provided with four radial baffles at its wall (width $b / T=1 / 10$ ) when the liquid aspect ratio $H / T=1$ (see Fig. 1). Tests were performed on five high-speed axial flow impellers of the same size (impeller-vessel diameter ratio $D / T=1 / 3$ located in the same position (impeller off-bottom clearance $C / D=3 / 4$ ) (see Figs. 1 and 2):

- Down pumping 4-blade pitched blade impeller $\left(\alpha=45^{\circ}, h / D=1 / 5\right)-4$ PRBT 45,

- Down pumping 6-blade pitched blade impeller $\left(\alpha=45^{\circ}, h / D=1 / 5\right)-6$ PBT 45,

- Down pumping 4-blade modified impeller $\left(\alpha=35^{\circ},(h / D)_{\mathrm{av}}=1 / 5\right)-\mathrm{TX} 535$,

- Down pumping 4-trapezoidal broken blade pitched blade impeller $\left(\alpha_{1}=45^{\circ}, \alpha_{2}=20^{\circ}\right.$, $\left.h_{1} / D=1 / 4, h_{2} / D=1 / 6\right)-\mathrm{TX} 445$,

- Down pumping 4-curved blade impeller with a high solidity ratio - TX 335.
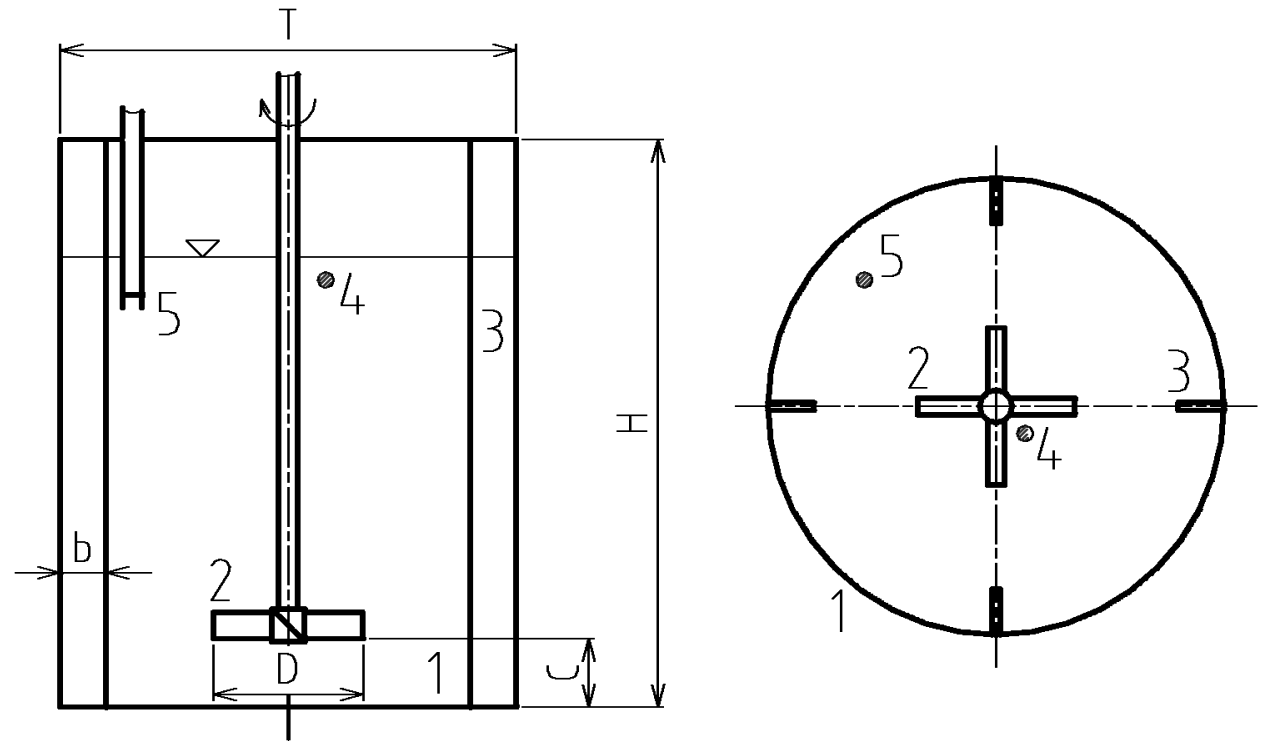

Fig. 1. Sketch of the pilot plant mixing vessel with 4 PBT 45,

1 - vessel, 2 - 4 PBT 45 impeller, 3 - baffle, 4 - position of the tracer addition, 5 - conductivity probe

\subsection{Blending time measurements}

After injecting a small amount of tracer $\Delta V$ (about $1 \mathrm{ccm}$ ) into the agitated liquid just below $(\mathrm{cca} 1 \mathrm{~cm}$ depth) the surface of the agitated charge in the vicinity of the impeller shaft changes of concentration and mixing time were measured in an appropriate location for measuring the blending time. This method is based on the principle of monitoring changes in the agitated liquid. The conductivity method was used for measuring the blending time. This method is based on the principle of monitoring changes in electrical conductivity within the mixed liquid. Changes in electrical conductivity were caused by adding a sample of concentrated solution of sodium chloride into the liquid. In our experiments the injected sample of the liquid had approximately the same density and viscosity as the mixed liquid, and thus the effect of the Archimedes number was eliminated. After adding the tracer, the time change of the conductivity was measured and recorded, and the blending time was determined. The conductivity 
cell consisted of two platinum wire electrodes $0.8 \mathrm{~mm}$ in diameter in the shape of a rectangle $8 \times 10 \mathrm{~mm}, 8 \mathrm{~mm}$ apart. The volume of the conductivity cell was approximately $0.8 \mathrm{ccm}$. The cell was located at one quarter of the height of the liquid below the surface of the mixed liquid and at one tenth of the vessel diameter from the wall of the vessel (see Fig. 1), in the midplane between two adjacent baffles. We chose this position because, during a test with the decolorisation method, a rather unmixed space had been detected in this volume for the impellers under investigation. The volume of the injected liquid varied in the range $0.5-1.0 \mathrm{ccm}$. The tracer was added to the batch by means of a syringe with a hypodermic needle for a few tenths of a second. The process of homogenisation was recorded with a fast chart recorder. The time of homogenisation (the blending time) was found at the moment when the fluctuation of the measured electrical voltage $U$ was $\pm 2 \%$.

The principle layout of the pilot plant experimental equipment is shown in Fig. 1. The blending time was determined for five geometric configurations; in all of the cases the impeller was pumping the liquid downwards - towards the bottom of the cylindrical vessel -and was located in its axis of symmetry.

A larger interval of the impeller Reynolds number was covered by using three different levels of viscosities of the tested liquids:

1. distilled water [viscosity $\mu$ around $1 \mathrm{mPa} \cdot \mathrm{s}$ ],

2. $25 \% \mathrm{w} / \mathrm{w}$ glycerol water solution [viscosity $\mu$ around $2 \mathrm{mPa} \cdot \mathrm{s}$ ],

3. $3.45 \% \mathrm{w} / \mathrm{w}$ glycerol water solution [viscosity $\mu$ around $4 \mathrm{mPa} \cdot \mathrm{s}$ ].

The accuracy of the data obtained depends significantly on the independent variables, i.e. the viscosity of the mixed liquid, the impeller speed and the geometric configuration of the agitated system. The impeller speed was measured by a photoelectric revolution counter with accuracy $\pm 1 \mathrm{rpm}$. The diameter of the impeller and the width of its blade were manufactured with accuracy $\pm 0.1 \mathrm{~mm}$ and the pitch angle within accuracy $\pm 30^{\prime}$. The impeller position in the vessel and the height of the liquid in the vessel were measured with a ruler with accuracy $\pm 1 \mathrm{~mm}$. The accuracy of the measurement of the dynamic viscosity was $\pm 0.1 \mathrm{mPa} \cdot \mathrm{s}$.

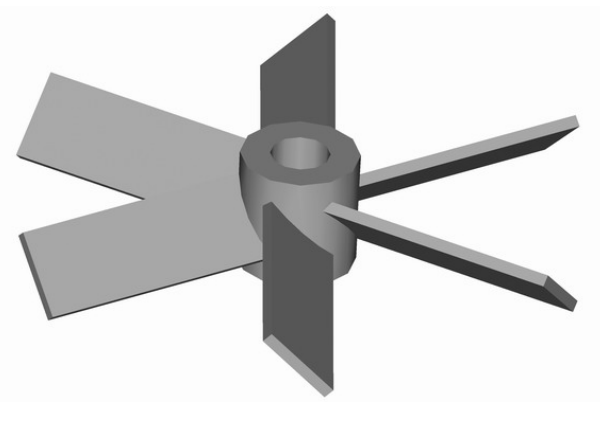

a)

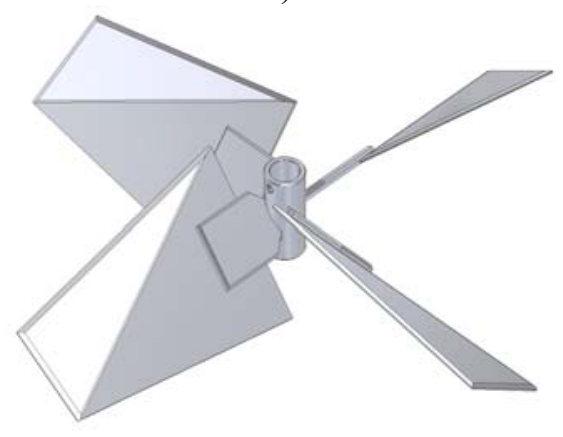

c)

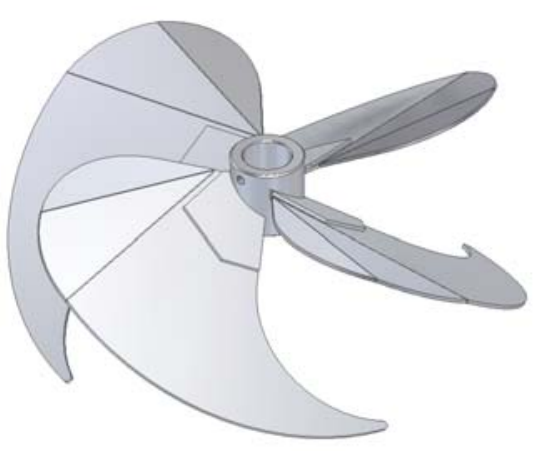

b)

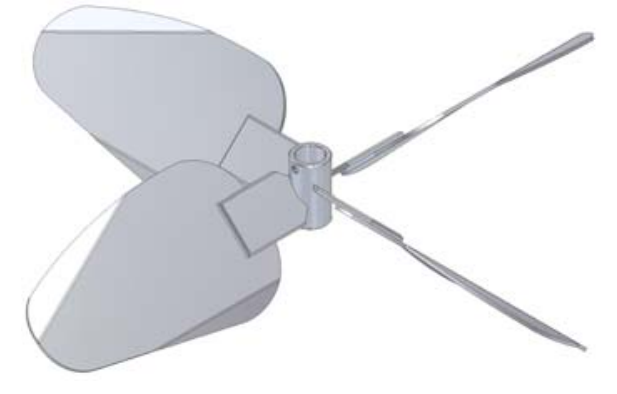

d)

Fig. 2. Tested axial high-speed impellers a) 6 PBT 45, b) TX 335, c) TX 445, d) TX 535 
Homogenisation was recorded with a fast chart calculation recorder with a scale $2.5 \mathrm{~mm} \sim 1$ second. The accuracy of the blending time measurement was considered $\pm 1 \mathrm{~s}$. For each configuration of the agitated system the blending time was measured at five different impeller speed values at constant viscosity of the mixed liquid. Because of the required confidence level of the final experimental results (Procházka and Landau, 1961), at least five courses of blending time for each impeller speed were determined and the average value for the given experiment was calculated. The blending time measured and calculated by this process exhibits a relative deviation of $\pm 2 \%$ from the calculated average value.

\subsection{Measurement of impeller power input}

The power input of the investigated impellers was calculated from an experimental determination of the torque and impeller speed. A strain gauge torquemeter, mounted on the motor shaft, was used to measure the torque, and the signal was fed into a data acquisition system. The impeller speed was measured by a photoelectric cell and a notched disc mechanism. This quantity was kept constant within $\pm 2 \mathrm{rpm}$ during the measurements. Therefore, the maximum experimental error encountered in measuring the speed was $1 \%$.

The main factors affecting the accuracy of impeller power input measurements were static friction and dynamic friction. The static friction effect was reduced to its minimum value by using a suitable bearing and driving motor. The most dominant factor, i.e. the dynamic friction, was closely monitored during the experiments to ensure that steady state torque values were recorded. For this purpose, the motor was allowed to run at high speed $(1000 \mathrm{rpm})$ for one hour before each set of experiments in order to reach the working temperatures of the bearings and the motor. The motor was then set to the lowest speed for the particular impeller and was allowed to run for 5 minutes until steady state conditions prevailed. Passive torque (the torque readings without installing the impeller) was then recorded for 3 minutes. Then the speed was increased by an increment of $40 \mathrm{rpm}$ and the passive torque was recorded again for 3 minutes, and so on until the maximum allowable rotational speed was reached. The motor started again at the lowest measuring speed and was left for 5 minutes before recording the torque. Torque data was then collected for 5 minutes, and three collections were recorded at each speed and off-bottom clearance to obtain the average power input. Passive torque was measured again at the end of each speed range. Then the relative standard deviation of the measured impeller power input was calculated and found to be in the range $2.3-10 \%$.

\section{RESULTS AND DISCUSSION}

The results of the experiments were evaluated from the point of view of Eq. (1), i.e. in the form

$$
P o^{1 / 3} n \Theta_{0.98}\left(\frac{D}{T}\right)^{2}=K_{0.98}
$$

Dimensionless blending time $n \Theta_{0.98}$ for a degree of homogeneity $I=0.98\left(I^{\prime}=0.02\right)$ was calculated for each tested impeller from the found dependence $n \Theta_{0.98}=n \Theta_{0.98}\left(R e_{M}\right)$, where the impeller Reynolds number

$$
\operatorname{Re}_{M}=\frac{n D^{2} \rho}{\mu}
$$

In accordance with the results of the cited authors (Fořt et al., 2001; Grenville and Nienow, 2003; Procházka and Landau, 1961), when quantity $R e_{M}$ exceeds ten thousand, the dimensionless blending time does not depend for the given degree of homogeneity on the impeller Reynolds number. The same relationship is valid between the power number (Eq. 2) and $R e_{M}$. Table 1 contains values of both 
calculated dimensionless quantities for all five tested axial flow high-speed impellers, and also parameter $K_{0.98}$ calculated from Eq. (9) for each impeller. Dimensionless blending time $n \Theta_{0.98}$ is always considered as the average value for the investigated interval of $\operatorname{Re}_{M}$ with its standard deviation, characterising the oscillation of blending time around its average value. Similarly, Table 2 contains the results of experiments performed by Forrt et al. (2001) for a three-blade pitched blade impeller in dependence on its pitch angle $\alpha$ and impeller-to-vessel diameter ratio $d / D$. Quantities $n \Theta_{0.98}$ and $P o$ were determined by the same experimental techniques in the same pilot plant mixing equipment with the same experimental accuracy as in this study, and are also valid for the turbulent regime of flow of an agitated liquid. Then the average value of parameter $K_{0.98 \text {,av }}$ from all 14 values of this parameter in Tables 1 and 2 amounts to

$$
K_{0.98, \mathrm{av}}=5.20
$$

with standard deviation $\pm 10 \%$. Moreover, it follows from the two Tables that it is possible to consider no significant correlation of parameter $K_{0.98}$ with the geometry and ratio $D / T$ of the tested impellers as well as with the power number.

Table 1. Values of parameter $K_{0.98}$ of Eq. (9) calculated from the experimental data of this study $-H / T=1, N_{\mathrm{b}}=4$, $b / T=1 / 10, D / T=1 / 3, C / D=3 / 4, I=0.98, R e_{\mathrm{M}}>1.5 \cdot 10^{4}$

\begin{tabular}{|c|c|c|c|}
\hline Impeller & Po & $n \Theta_{0.98}$ & $K_{0.98}$ \\
\hline 4 PBT 45 & 1.29 & $46.5 \pm 1.5$ & 5.62 \\
6 PBT 45 & 1.65 & $39.05 \pm 2.3$ & 5.13 \\
TX 335 & 0.905 & $44.7 \pm 1.5$ & 4.80 \\
TX 445 & 0.90 & $45.9 \pm 1.4$ & 4.92 \\
TX 535 & 0.646 & $51.7 \pm 1.4$ & 4.96 \\
\hline
\end{tabular}

Table 2. Values of parameter $K_{0.98}$ of Eq. (9) calculated from experimental the data of Fořt et al. $(2001)-H / T=1$, $N_{\mathrm{b}}=4, R e_{\mathrm{M}}>1.5 \cdot 10^{4}$, three-blade pitched blade impeller $(h / D=1 / 5), C / D=1, I=0.98$

\begin{tabular}{|c|c|c|c|c|}
\hline$\alpha[\mathrm{deg}]$ & $D / T$ & $P o$ & $n \Theta_{0.98}$ & $K_{0.98}$ \\
\hline 24 & $1 / 2$ & 0.39 & $32.8 \pm 2.0$ & 5.98 \\
35 & $1 / 2$ & 0.80 & $25.3 \pm 1.3$ & 5.87 \\
45 & $1 / 2$ & 1.23 & $18.6 \pm 1.0$ & 4.98 \\
24 & $1 / 3$ & 0.34 & $60.3 \pm 4.2$ & 4.67 \\
35 & $1 / 3$ & 0.69 & $58.7 \pm 2.7$ & 5.76 \\
45 & $1 / 3$ & 1.06 & $49.2 \pm 1.2$ & 5.35 \\
24 & 0.222 & 0.29 & $142.0 \pm 8.1$ & 4.63 \\
35 & 0.222 & 0.59 & $118.0 \pm 11.2$ & 4.88 \\
45 & 0.222 & 0.92 & $112.0 \pm 10.5$ & 5.36 \\
\hline
\end{tabular}

Table 3. Comparison of blending time for degree of homogeneity $95 \%$ and $98 \%\left(n=133 \mathrm{rpm}, \operatorname{Re}_{\mathrm{M}}=2.25 \cdot 10^{4}\right)$

\begin{tabular}{|c|c|c|c|c|}
\hline Impeller & $n \Theta_{0.95}$ & $n \Theta_{0.98}$ & $n \Theta_{0.98} / n \Theta_{0.95}$ & $\left(n \Theta_{0.98} / n \Theta_{0.95}\right)_{\text {theor }}$ \\
\hline 6 PBT 45 & $28.6+/-2.2$ & $37.1+/-2.8$ & $1.30 \pm 0.10$ & 1.305 \\
TX 335 & $34.4+/-3.5$ & $44.7+/-4.3$ & $1.30 \pm 0.08$ & 1.305 \\
\hline
\end{tabular}

Table 3 presents a comparison of the blending time for two levels of homogeneity degree $I=0.98$ and $0.95\left(I^{\prime}=0.02\right.$ and 0.05$)$ calculated from the experimental data of two types of the tested axial impellers - 6PBT 45 and TX 335 - at the selected impeller speed level. The last column in the Table depicts this 
ratio according to the theoretical approach - Eq. (8). The average dimensionless blending time values are accompanied by their standard deviations. It follows from Table 3 that the experimentally determined value of quantity $n \Theta_{\text {I }}$ can be recalculated from one degree of homogeneity $I$, resp. $I^{\prime}$, to another degree of homogeneity in accordance with its logarithmic dependence expressed by Eq. (8).

The value of parameter $K_{0.98 \text {,av }}$ in Eq. (11) confirms the approach of Grenville and Nienow (2003), which expresses the universal relation between the energetic and blending criterion of axial high-speed impellers, taking into consideration their impeller-to-vessel diameter ratio. However, this value is the same as the value of this quantity valid for a degree of homogeneity $I^{\prime}=0.95$ (see Eq. 1). When we consider the conclusion drawn by Grenville and Nienow (2003), that at least for pilot plant mixing equipment the position of the conductivity cell does not affect the time course of the blending process, the only reason for different levels of quantity $I^{\prime}$ in Eqs. (1) and (9) can be the way of putting the sample into an agitated charge. The value of parameter $K_{0.98, \text { av }}$ in Eq. (11) confirms a faster blending process than the process illustrated by the value of the parameter on the right hand side of Eq. (1). In this study, the volumetric flow rate of the liquid injected just below the surface of the charge along the shaft in axial (vertical) direction was approx. $2 \mathrm{ccm} \mathrm{s}^{-1}$ at axial velocity about $0.6-0.7 \mathrm{~m} \mathrm{~s}^{-1}$. Such a value significantly exceeds the axial velocity (vertical component of the mean velocity) at the injection point (Forrt, 1986) and results in a rather short time of the path of the sample between the positions of its appearance and its contact with the rotating impeller (cca $0.3 \mathrm{~s}$ for all the five tested axial high-speed impellers). Then the volume of the sample is dispersed via its interference with the impeller blades and, further, its uniform distribution in the impeller discharge stream can be assumed. Thus the time changes of the concentration in the agitated charge can be considered as three dimensional due to the primary circulation of the agitated liquid in its whole volume. Such propagation of the concentration signal in an agitated batch seems to be rather effective and corresponds to the most convenient position of the feed-tube outlet in the continuous-flow stirred reactor (Mavros et al., 2002) (CFSTR) when the incoming flow from the inlet tube (oriented into the impeller rotor region) is parallel with the outflow from this volume. Recently Liu (2011a) published a study on flow behavior of CFSTR with some consequences for blending in batch agitated system. He confirmed a mutual interference between positions of inlet and outlet tube and measured or calculated blending time for a chosen homogeneity degree. When the direction of the incoming flow is parallel with the direction of the outflow, the blending time measured in the vicinity of the outlet tube is shorter than in case when these tubes exhibit perpendicular position. More recently Liu (2011b) confirmed our finding that Grenville and Nienow (2003) mentioned the application of three probes during the previous experiments of Grenville, two of them located in the flow main loop and the third one near the baffle being in the main loop as well. These results confirm that the blending time calculated by Eq. (1) is not the slowest but an average value of this quantity in the main loop in the mixing vessel. Then due to the complexity of the flow in investigated agitated system attention has to be paid when comparing different results of blending time.

Finally, it is worth mentioning why the chosen degree of homogeneity $I^{\prime}$ in this study was $98 \%$, and not the widely used value of $95 \%$. It follows from the requirements of industrial blending processes (Seichter and Pešl, 2005) (e. g. in polymerisation reactors and in reactors for producing inorganic pigments) to reach the final degree of homogeneity of at least $98 \%$.

\section{CONCLUSIONS}

Under a turbulent flow regime of an agitated liquid there is a universal relationship between the impeller power number, the dimensionless blending time and the impeller-to-vessel diameter ratio that is independent of the geometry of the axial flow impeller but dependent on the degree of homogeneity of the agitated charge. 
The authors of this paper appreciate financial support from the Czech Ministry of Industry and Trade (Grant No. FR - T11/005).

\section{SYMBOLS}

$b \quad$ width of radial baffle, $\mathrm{m}$

C impeller off-bottom clearance, $\mathrm{m}$

C parameter in Eq. 6

C concentration, $\mathrm{kg} \mathrm{m}^{-3}$

D impeller diameter, $\mathrm{m}$

$H \quad$ height of agitated charge above vessel bottom, $\mathrm{m}$

$h \quad$ impeller blade width, $\mathrm{m}$

$h_{1} \quad$ impeller blade width at the hub, $\mathrm{m}$

$h_{2} \quad$ impeller blade width at blade edge, $\mathrm{m}$

I degree of homogeneity according to Eq. 3

$I^{\prime} \quad$ degree of homogeneity according to Eq. 4

$K \quad$ parameter in Eq. 9

$L \quad$ parameter in Eq. 6

$N_{\mathrm{b}} \quad$ number of baffles

$n \quad$ impeller speed, $\mathrm{s}^{-1}$

$P \quad$ impeller power input, $\mathrm{W}$

Po power number

$R e_{\mathrm{M}} \quad$ impeller Reynolds number

$T \quad$ mixing vessel diameter, $\mathrm{m}$

$U \quad$ electrical voltage, $\mathrm{V}$

Greek symbols

$\alpha \quad$ pitch angle of blade, ${ }^{\circ}$

$\Theta \quad$ blending time, $\mathrm{s}$

$\mu \quad$ dynamic viscosity, Pa.s

$\rho \quad$ density, $\mathrm{kg} \mathrm{m}^{-3}$

\section{Subscripts}

av average value

theor theoretical value

$0 \quad$ initial value

$\infty \quad$ final value

\section{REFERENCES}

Fořt I., 1989. Flow and turbulence in vessels with axial impellers, In: Uhl V.W., Gray J.B. (Eds.), Mixing, theory and practice, Vol. III. Academic Press, New York, 133 - 197.

Fořt I., Jirout T., Rieger F., Allner R., Sperling R., 2001. Study of the blending efficiency of pitched blade impellers. Acta Polytechnica, 41, 7 - 13.

Grenville R. K., Nienow A. W., 2003. Blending in miscible liquid, In: Paul E. L., Otiemo-Obeng V. A., Kresta S. M. (Eds.), Industrial mixing. Science and practice. Wiley Interscience, New York, 507 - 542.

Khang S. J., Levenspiel O., 1976. New scale-up and design criteria for stirrer agitated batch mixing vessels. Chem Eng. Sci., 31, 569-577. DOI: 10.1016/0009-2509(76)80020-6.

Kramers H., Baars G. M., Knoll W. H., 1953. A comparative study on the rate of mixing in stirred tanks. Chem. Eng. Sci., 2, 35-42. DOI: 10.1016/0009-2509(53)80006-0. 
Liu M., 2011a. Prediction of tracer concentration and mixing in CFSTR with mean age distribution. Ind. Eng. Chem. Res., 50, 5838 - 5851. DOI: 10.1021/ie2002395.

Liu M., 2011b. Quantitative characterisation of mixing in stirred tank reactors with mean age distribution. Can. Jour. Chem. Eng., 89, 1018-1028. DOI: 10.0122/cjce.20563.

Mavros P., Xuereb C., Fořt I., Bertrand J., 2002. Investigation by laser Doppler velocimetry of the effects of liquid flow rates and feed positions on the flow patterns induced in a stirred tank by an axial - flow impeller. Chem. Eng. Sci., 57, 3939 - 3952. DOI: 10.1016/0009-2509(02)00268-3.

Nienow A. W., 1997. On impeller circulation and mixing effectiveness in the turbulent regime. Chem. Eng. Sci., 52 , 2557-2565. DOI: 10.1016/0009 - 2509(97)00072-9.

Procházka J., Landau J., 1961. Homogenization of miscible liquids by rotary impellers. Collect. Czech. Chem. Commun., 26, 2961-2974.

Seichter P., Pešl L., 2005. Design of rotary impellers - science or art? CHEMagazin, 15(2), 8-11 (in Czech). 